\title{
A citizen science approach to monitoring bleaching in the zoantharian Palythoa tuberculosa
}

John Everett Parkinson, Sung-Yin Yang, lori Kawamura, Gordon Byron, Peter Todd, James Davis Reimer

Coral reef bleaching events are expected to become more frequent and severe in the near future as climate changes. The zoantharian Palythoa tuberculosa bleaches earlier than many scleractinian corals and may serve as an indicator species. Basic monitoring of such species could help to detect and even anticipate bleaching events, especially in areas where more sophisticated approaches that rely on buoy or satellite measurements of sea surface temperature are unavailable or too coarse. One simple and inexpensive monitoring method involves training volunteers to record observations of host color as a proxy for symbiosis quality. Here, we trained university students to take the 'color fingerprint' of a reef by assessing the color of multiple randomly selected colonies of $P$. tuberculosa at one time point in Okinawa Island, Japan. We tested the reliability of the students' color scores and whether they matched expectations based on previous monthly monitoring of tagged colonies at the same locations. We also measured three traditional metrics of symbiosis quality for comparison: symbiont morphological condition, cell density, and chlorophyll a content. We found that $P$. tuberculosa color score, although highly correlated among observers, provided little predictive power for the other variables. This was likely due to inherent variation in colony color among generally healthy zoantharians in midwinter, as well as low sample size and brief training owing to the course structure. Despite certain limitations of $P$. tuberculosa as a focal organism, the citizen science approach to color monitoring has promise, and we outline steps that could improve similar efforts in the future. 
1 A citizen science approach to monitoring bleaching in the zoantharian Palythoa tuberculosa 2

3 John Everett Parkinson ${ }^{1}$, Sung-Yin Yang ${ }^{1,2}$, Iori Kawamura ${ }^{1}$, Gordon Byron ${ }^{1,3}$, Peter Todd ${ }^{4}$, \&

4 James Davis Reimer ${ }^{1,5}$

5

$6{ }^{1}$ Molecular Invertebrate Systematics and Ecology Laboratory, Department of Chemistry,

7 Biology, and Marine Science, Faculty of Science, University of the Ryukyus, Nishihara,

8 Okinawa, Japan

$9{ }^{2}$ Microbiology and Biochemistry of Secondary Metabolites Unit, Okinawa Institute of Science

10 and Technology Graduate University, Onna, Okinawa, Japan

$11{ }^{3}$ Reef Ecology Laboratory, King Abdullah University of Science and Technology, Thuwal, Saudi

12 Arabia

$13{ }^{4}$ Experimental Marine Ecology Laboratory, National University of Singapore, Republic of

14 Singapore

$15{ }^{5}$ Tropical Biosphere Research Center, University of the Ryukyus, Nishihara, Okinawa, Japan 16

17 Correspondence: John Everett Parkinson, Molecular Invertebrate Systematics and Ecology

18 Laboratory, Department of Chemistry, Biology, and Marine Science, Faculty of Science,

19 University of the Ryukyus, 1 Senbaru, Nishihara, Okinawa, Japan, 902-0213. E-mail:

20 jparkinson@psu.edu 


\section{Abstract}

22 Coral reef bleaching events are expected to become more frequent and severe in the near

23 future as climate changes. The zoantharian Palythoa tuberculosa bleaches earlier than many

24 scleractinian corals and may serve as an indicator species. Basic monitoring of such species

25 could help to detect and even anticipate bleaching events, especially in areas where more

26 sophisticated approaches that rely on buoy or satellite measurements of sea surface temperature

27 are unavailable or too coarse. One simple and inexpensive monitoring method involves training

28 volunteers to record observations of host color as a proxy for symbiosis quality. Here, we trained

29 university students to take the 'color fingerprint' of a reef by assessing the color of multiple

30 randomly selected colonies of $P$. tuberculosa at one time point in Okinawa Island, Japan. We

31 tested the reliability of the students' color scores and whether they matched expectations based

32 on previous monthly monitoring of tagged colonies at the same locations. We also measured

33 three traditional metrics of symbiosis quality for comparison: symbiont morphological condition,

34 cell density, and chlorophyll $a$ content. We found that $P$. tuberculosa color score, although

35 highly correlated among observers, provided little predictive power for the other variables. This

36 was likely due to inherent variation in colony color among generally healthy zoantharians in

37 midwinter, as well as low sample size and brief training owing to the course structure. Despite

38 certain limitations of $P$. tuberculosa as a focal organism, the citizen science approach to color

39 monitoring has promise, and we outline steps that could improve similar efforts in the future. 


\section{Introduction}

Visible loss of color among zooxanthellate cnidarian colonies can reflect a stress-induced breakdown of the mutualistic relationship between hosts and their endosymbiotic algae, dinoflagellates of the genus Symbiodinium Freudenthal. As the association deteriorates, reductions in photosynthetic pigment levels and/or healthy Symbiodinium densities dampen the color intensity of the colony (Fitt et al. 2001). Bleaching is driven by many factors, chief among them increasing sea surface temperatures associated with ongoing climate change (Brown 1997). Mass bleaching events have been observed in almost all subtropical and tropical reef areas (Wilkinson 1998; Goldberg and Wilkinson 2004; Donner et al. 2005), sometimes causing extensive mortality of hard corals (e.g. Glynn et al. 2001; Loya et al. 2001; Depczynski et al. 2013), soft corals (e.g. Harvell et al. 2001; Prada et al. 2010; Dias and Gondim 2015), and zoantharians (e.g. Williams and Bunkley-Williams 1990; Goldberg and Wilkinson 2004). Bleaching is one of the most serious problems facing the long-term survival of coral reef ecosystems (Hoegh-Guldberg 1999), especially as models predict bleaching to become an annual event for many reefs in the near future (Donner et al. 2005; Van Hooidonk et al. 2013). Thus, detecting and predicting bleaching events on broad and local scales has become a key component of monitoring the health of coral reef ecosystems (Andréfouët et al. 2002; Eakin et al. 2009).

Although buoy and satellite-based products have greatly improved our capacity to anticipate bleaching events (Eakin et al. 2009), the data are not always readily available in certain areas, and local variability such as infrequent upwelling or freshwater input may necessitate targeted observation. For many managers monitoring reefs at the local scale, it is often advantageous to take a citizen science approach, and to adopt simplified tools and techniques that are easily taught to volunteers (Hunter et al. 2013). One example is the 'CoralWatch Coral Health Chart' (Siebeck et al. 2006), a waterproof card featuring standardized color squares for determining changes in bleaching status. In practice, observers compare the reference card and a host colony in situ, scoring colors on a saturation scale ranging from one to six (Siebeck et al. 2006; Siebeck et al. 2008). These scores correlate with chlorophyll a concentrations and Symbiodinium densities in hard corals (Siebeck et al. 2006) and to some degree with the morphological condition of Symbiodinium in zoantharians (Hibino et al. 2013). The method can scale to track colonies, species, or communities, and has been used to monitor 
71 reef symbiosis quality over time (Cooper et al. 2009; Montano et al. 2010; Marshall et al. 2012; 72 Paley and Bay 2012; Tanzil 2012).

Color cards are also recommended for taking a 'fingerprint' of the reef condition, which

involves observing a random cross-section of colonies at a single time point (Siebeck et al. 2008). Not to be confused with other techniques like DNA fingerprinting, 'color fingerprinting' is an alternative to repeatedly observing tagged colonies ('recurrent monitoring'). Although less precise than recurrent monitoring, color fingerprinting does have the power to detect differences within and among bleaching and recovered reefs, and is more suitable for non-specialists than recurrent monitoring because the method does not require a permanent transect or tagged colonies (Siebeck et al. 2008). Certain anthozoans such as Acropora, Millepora, and Palythoa in particular tend to visibly bleach sooner than other members of the reef community (Williams and Bunkley-Williams 1990; Wilkinson 1998). These 'early-indicator' species might serve as useful color fingerprinting targets to anticipate changes in bleaching condition at a given site.

The zoantharian Palythoa tuberculosa (Esper) is broadly distributed throughout the IndoPacific, from Madagascar to the Red Sea to Japan (Reimer et al. 2006). It is abundant in shallow waters, easily observed via snorkeling, and free from legal protections that limit sampling of other cnidarians, making it a practical candidate for observation. It has been suggested that certain Caribbean Palythoa species should not be used as indicators because their "bleaching" has not correlated with temperature or season and may have simply reflected natural color variation (Cook et al. 1990). Moreover, many zoantharians incorporate calcareous sand into their bodies, potentially affecting color (e.g. West 1979). However, in 2009 Hibino et al. (2013) monitored 12 tagged colonies of P. tuberculosa monthly in Okinawa Island, Japan, and found that many colonies paled during periods of rapidly elevating sea surface temperature (e.g. from $21^{\circ} \mathrm{C}$ to $25^{\circ} \mathrm{C}$ in 3 weeks) and that colony color correlated with symbiont morphological condition. Thus, continued P. tuberculosa color observation at this location seems warranted, though in need of additional testing.

Here, our goal was to further develop methodologies for monitoring zoantharian bleaching condition by incorporating citizen scientists in color score assessment and testing the accuracy and utility of their data. In January 2014, we trained 12 student volunteers during a two-day course in the use of the CoralWatch Coral Health Chart. The students scored 20 new colonies of $P$. tuberculosa from Okinawa Island at the same locations described by Hibino et al. 
102 (2013). To determine whether the data acquired by naïve observers were reliable, we compared

103 color scores among the students, who were trained together but worked independently on the

104 same colony images. To assess whether color corresponded to symbiosis quality, we also

105 measured three alternative metrics: symbiont morphological condition, cell density, and

106 chlorophyll $a$ content. Finally, we placed the new color fingerprinting data in context by

107 comparing them to the previously published recurrent monitoring time series data. 
109 Materials \& Methods

110 Training for color card scoring and Symbiodinium morphological condition observation

111 Twelve undergraduate students from the University of the Ryukyus were trained as part

112 of a two-day practical course using images of Palythoa tuberculosa and Symbiodinium sp.

113 collected previously as part of a year-long monitoring project (Hibino et al. 2013). During

114 lecture, students were shown 20 images of $P$. tuberculosa colonies and asked to independently

115 score colony colors with reference to 'CoralWatch Coral Health Chart' color cards included in

116 the photographs. Color was scored from a low of 0.0 (completely white) to a high of 6.0 (very

117 dark) by increments of 0.5 (as by Hibino et al. 2013), effectively doubling the resolution of the

118 original scale (Siebeck et al. 2006). Additionally, students were shown 20 slides of

119 Symbiodinium cells collected from the same colonies and asked to independently classify

120 Symbiodinium morphological conditions. Each student calculated the percentage of 'normal'

121 (non-degraded) zooxanthellae (NZ\%) according to Reimer et al. (2007). The instructor checked

122 student color scores and NZ\% values against those of Hibino et al. (2013) to confirm accuracy.

123 Because deviations were generally low, students were deemed competent for field work.

124

125 Colony collection, image capture, and color scoring

126 Two locations in Okinawa, Japan, were included in our color fingerprinting assessment

127 and matched those sampled by Hibino et al. (2013): Odo Beach (26 $\left.05^{\prime} \mathrm{N}, 127^{\circ} 42^{\prime} \mathrm{E}\right)$ in Itoman

128 City, and Mizugama (26² 'N, $127^{\circ} 44^{\prime} \mathrm{E}$ ), in Kadena Town, very close to Miyagi beach (for a

129 map, see Figure 1 of Hibino et al. 2013). Colonies were sampled in the early afternoon of 12 Jan.

130 2014, when the intertidal zones of Odo and Mizugama were submerged. At both locations, 10

131 colonies of $P$. tuberculosa were selected haphazardly from the intertidal zone. All colonies were

$132>50 \mathrm{~cm}^{2}$, separated by $>5 \mathrm{~m}$, and positioned at depths $<2 \mathrm{~m}$.

133 Digital images of each colony were taken in situ with an underwater camera. A laminated

134 'CoralWatch Health Chart' color card was placed by each colony and included in the

135 photograph, allowing for standard comparisons regardless of variable light levels or camera

136 equipment. Color scores were later assessed independently by all 12 trained observers from the

137 digital images. Because P. tuberculosa colonies occasionally possess some darker and lighter

138 areas, the score was based on the most typical intermediate shade accounting for most of the

139 colony's area. Immediately after the photographs were taken, fragments $\left(\sim 5 \mathrm{~cm}^{3}\right)$ of each colony 
140 were sampled with a diving knife and placed into individually marked sealable plastic bags. The

141 bags were then placed in a $15 \mathrm{~L}$ bucket filled with ambient seawater and taken back to the

142 laboratory at the University of the Ryukyus. Total transit time was $<1 \mathrm{~h}$.

143 Symbiodinium morphological condition, cell density, and chlorophyll a content

144 The freshly collected P. tuberculosa fragments were further processed in the laboratory.

145 Symbiodinium cell preparation followed Hibino et al. (2013). Briefly, host tissue was macerated,

146 homogenized, resuspended in $1 \mathrm{ml}$ seawater, and spread on a hemocytometer (Thoma EKDS,

147 1/10 mm depth). Symbiodinium cells were visualized at 400× magnification with a light

148 microscope and photographed ( $\mathrm{n}>100$ cells per specimen). Cells were then tallied from the

149 images according to the morphological condition classification scheme described by Reimer et

150 al. (2007) based on previous studies (Kuroki and Van Woesik 1999; Mise and Hidaka 2003).

151 Each student performed his or her own assessment to calculate NZ\%.

152 Additional tissue from the P. tuberculosa fragments ( $1 \mathrm{~cm}^{3}$ each) was used to calculate

153 Symbiodinium cell densities. The tissue was processed and visualized as above, with the added

154 step of using fine calipers to cut exact tissue dimensions so that relative densities would be

155 directly comparable. Cell density per colony was calculated as the total number of cells observed

156 divided by the total volume observed. Again, each student performed his or her own assessment.

157 To determine symbiont-derived chlorophyll $a$ content in each P. tuberculosa colony,

158 Symbiodinium cells were isolated following Richier et al. (2003) and Wang et al. (2011). Briefly,

159 calipers were used to cut $1 \mathrm{~cm}^{3}$ of tissue which was then macerated, homogenized, allowed to

160 settle, cleaned through serial resuspension in seawater, and finally resuspended in $2 \mathrm{ml}$ of $90 \%$

161 acetone and preserved at $4{ }^{\circ} \mathrm{C}$ overnight. The next day, chlorophyll $a$ measurement followed

162 Jeffrey and Humphrey (1975) and was performed on a Shimadzu UV-1800 UV

163 spectrophotometer with absorbances at 630, 647, and $664 \mathrm{~nm}$. Chlorophyll $a$ content was

164 standardized to the volume of the $P$. tuberculosa sample. Only one measurement was made per

165 colony by an instructor; students did not contribute to this analysis.

167 Statistical analyses

168 All analyses were performed in the R statistical environment. The original data files and

169 R script can be accessed in Supplemental Data S1. Statistical significance was assessed at $\alpha<$

$170 \quad 0.05$. For each colony in the study, color score was averaged from the values recorded by all 12 
171 student observers, and coefficients of variation (standard deviation / mean) were calculated to

172 estimate among-observer error. Reliability and correlation among student color scores were

173 assessed with Krippendorf's alpha and Spearman's rho coefficients, respectively. Confidence

174 intervals were generated via jackknife.

175 To investigate associations between color scores and other metrics, Spearman's rho

176 coefficients were calculated with symbiont morphological condition (NZ\%), cell density, or

177 chlorophyll $a$ content. Spearman's rho was used instead of Pearson's rho because the color scale

178 is not continuous. For these calculations, the average color score per colony was rounded to the

179 nearest 0.5 (or, if exactly intermediate, rounded down). For symbiont morphological condition

180 and cell density, the unrounded average was used. For chlorophyll $a$ content, the single measured

181 value was used.

182 For comparative purposes, we reanalyzed the previously published time series data

183 (Hibino et al. 2013; with permission). This earlier monitoring work was performed at or near the

184 same two Okinawan locations and focused on the same host species, $P$. tuberculosa. It includes

185 monthly color score and NZ\% data collected from 12 tagged colonies throughout 2009.

186 Correlations between raw color score and NZ\% were again calculated with Spearman's rho. 


\section{Results}

189 Color score variation

190 Palythoa tuberculosa colonies at Odo Beach and Mizugama exhibited a moderate degree

191 of color variation among different individuals (Fig. 1). Average colony color scores in this study

192 ranged from 3.50 to 5.63, corresponding to a rounded range of 3.5 to 5.5. This span is typically

193 associated with healthy colonies (Siebeck et al. 2006; Siebeck et al. 2008). Agreement among

194 observers was generally high. Most scores fell within \pm 1.0 of the rounded observer average (Fig.

195 2A). Accordingly, associated coefficients of variation were small relative to the interval size of

1960.5 (mean CV: $0.10 \pm 0.02$ s.d.). However, for one colony (O7), the color score ranged from a

197 low of 3.0 to a high of 6.0 , spanning 7 intervals.

$198 \quad$ Krippendorf's alpha is a metric of agreement among observers scoring identical subjects

199 on a common scale. In the absence of systemic bias, it ranges from 0 (no reliability) to 1 (perfect

200 reliability), and values $<0.667$ are considered unreliable (Krippendorff 2004). Observed alpha

201 fell below this threshold (mean $\alpha=0.555,95 \%$ CI $[0.534,0.574]$ ). Spearman's rho is a

202 nonparametric measure of correlation that characterizes the extent to which two variables are

203 described by a monotonic function. It ranges from -1 (perfect negative correlation) to 0 (no

204 correlation) to +1 (perfect positive correlation). Observed rho among observers was positive

205 (mean $\rho=0.633,95 \%$ CI $[0.590,0.661])$.

206

207

\section{Correlations among variables}

Mean symbiont morphological condition (NZ\%) ranged from 71.0 to $86.8 \%$ normal (Fig.

209

2B). Mean symbiont cell density ranged from $0.18 \times 10^{6}$ to $1.96 \times 10^{6}$ cells cm$^{-3}$ (Fig. $2 \mathrm{C}$ ).

Chlorophyll $a$ concentration ranged from 2.4 to $18.2 \mu \mathrm{g} \mathrm{cm}^{-3}$ (Fig. 2D). Color score trended

211 toward a slightly negative but statistically insignificant correlation with chlorophyll $a$ ( $\rho=$ -

$\left.2120.472, p_{a d j}=0.215\right)$, and had no relationship with symbiont morphological condition $(\rho=-0.027$,

$\left.213 p_{a d j}=1\right)$ or cell density $\left(\rho=-0.030, p_{a d j}=1\right)$.

215 Comparisons between color fingerprinting and recurrent monitoring time series data

216 From January to November 2009, the color score distributions for 12 repeatedly sampled

217 P. tuberculosa colonies were fairly consistent, with most scores lying in the range from 3.5 to

218 5.0, the exception being summer months, when some colonies scored as low as 2.5 (Fig. 3A). 
219 Color score and symbiont morphological condition (NZ\%) were only significantly positively

220 correlated in summer months (Fig. 3B), for example, in May ( $\rho=0.753, p_{a d j}=0.004$; Fig. 4A)

221 and June ( $\rho=0.726, p_{a d j}=0.009$; Fig. 4B). When January 2009 recurrent monitoring data were

222 compared to the color fingerprinting data from January 2014 (Fig. 4C vs. Fig. 4D), both

223 distributions were similar, with most colonies exhibiting healthy color and NZ\% ranges and no 224 correlation between metrics. 


\section{Discussion}

227 Reef managers are faced with many options when deciding how to allocate limited 228 resources to enhance local conservation efforts. The 'CoralWatch Coral Health Chart' was

229 developed as a low-cost, non-invasive technique for assessing reef health (Siebeck et al. 2006).

230 Recurrently monitoring individual colonies and color fingerprinting random colonies have both

231 been proposed as effective citizen science methods (Siebeck et al. 2008). Using the potential

232 'early-indicator' zoantharian Palythoa tuberculosa from Okinawan reefs, we found that both

233 techniques complement each other and work best when used in conjunction, in line with the

234 recommendations from CoralWatch. However, zoantharian-based color monitoring programs

235 face unique problems that may restrict their utility.

236 It can be difficult to ensure data validity in any citizen science program (Foster-Smith and

237 Evans 2003), but the issue is compounded for color surveys in marine environments. Human

238 color perception is inherently variable and affected by altered spectral properties underwater

239 (Neitz and Jacobs 1986; Winters et al. 2009). While the color cards are designed to reduce

240 subjectivity, there are also issues regarding natural color variation among cnidarian symbioses.

241 For example, the number of symbiont cells in a given colony increases and decreases seasonally

242 (Fitt et al. 2001), and coral colonies that appear white are not necessarily bleached or

243 compromised (Cruz et al. 2015). Both sources of variation presented challenges in this study.

244 Based on low between-observer error in color scores, volunteers were successfully

245 trained to moderate skill levels quickly. The high correlation among individuals (Spearman's $\rho=$

2460.633 ) despite a low reliability statistic (Krippendorf's $\alpha=0.555$ ) meant observers consistently

247 ranked colonies in similar order, though often failed to assign exactly the same scores. Despite

248 absolute score discrepancies, deviations remained low and even the inclusion of a difficult-to-

249 score colony $(\mathrm{O} 7)$ did not unduly influence the reliability or correlation measures. One major

250 advantage of color fingerprinting over recurrent monitoring is that more volunteers can typically

251 be included, so losses in color accuracy due to the involvement of many non-experts can be

252 offset by averaging observations. When designing volunteer surveys, the best practice appears to

253 be to maximize the number of colonies that are photographed, and afterwards to have as many

254 individuals as possible (at least 3-4) score every image independently. This improves confidence

255 that the rounded mean color score reflects the true color. 
However, accurate color measurement does not matter if color is not indicative of

257

258

259

260

261

262

263

264

265

266

267

268

269

270

271

272

273

274

275

276

277

278

279

280

281

282

283

284

285

286 symbiosis quality. Based on our color fingerprinting data from January 2014, we found that color scores did not predict the values of more invasive metrics such as symbiont morphological condition, cell density, or chlorophyll $a$ content (Fig. 2). Only observations from relatively stressful warm summer months resulted in high correlations among color and symbiont morphological condition (Fig. 3B, Fig. 4), suggesting the utility of the color score approach depends upon the presence of compromised colonies with low symbiosis quality. During the cool subtropical winter, most $P$. tuberculosa colonies were healthy, having high percentages of 'normal' (non-degraded) zooxanthellae, high symbiont cell densities, and generally high color scores. As noted in the original description of the color card technique, the relationship between color and other metrics is weakest among darker, healthier colonies (Siebeck et al. 2006). This points to a general issue with color data; while it can be good for detecting bleached colonies (but see Cruz et al. 2015), it is potentially uninformative for healthy colonies above certain thresholds, which are likely species- or location-specific (Kemp et al. 2006). A large degree of natural color variation makes $P$. tuberculosa a problematic focal species for bleaching monitoring.

Our results suggest a single color fingerprinting data set does not appear to be useful on its own, unless the goal is to compare several reefs within a management area simultaneously (e.g. Siebeck et al. 2008). One isolated snapshot can be difficult to interpret without a baseline for comparison, especially during winter months. Our combined analyses of Okinawan $P$. tuberculosa colonies from 2009 and 2014 indicates that data generated from color fingerprinting reflect a major trend from recurrent monitoring; namely that under winter conditions colonies are generally healthier and darker (Fig. 3A). Hence, the two methods can complement each other. For example, using the $P$. tuberculosa recurrent monitoring results as a predictor, we anticipate that color fingerprinting anywhere from April to August will include a broad range of colors and health conditions. A deviation from this trend (such as an overrepresentation of lighter colonies) may signify bleaching conditions on a reef. However, the exact expectation of which months will be useful to survey will vary by species and reef, which is why local baseline data are so crucial. If feasible, we encourage reef managers to adopt a combined approach to color observation: first having specialists track tagged colonies over the course of a year, then having volunteers fingerprint during critical time periods. 
This particular citizen science effort was structured around a university field course, 288 presenting some unique difficulties. The training period was brief (two days in a classroom 289 setting), and while students appeared consistent in their scoring of reference photographs, more 290 training might have improved the reliability of their data. We were also limited in the time 291 available for sample collection. We sampled only 20 colonies, falling far short of the standard set 292 by other studies (e.g. 100 colonies; Siebeck et al. 2008). Finally, the course was scheduled for 293 winter, though it would have been more ecologically relevant to sample in summer. These 294 limitations point to several avenues for further development of zoantharian color monitoring 295 programs. Future work could test the impact of training duration on color score reliability, or 296 examine bleaching summers vs. non-bleaching summers. Photochemical interrogation via pulse297 amplitude modulated (PAM) fluorometry could be used to determine whether zoantharian 298 symbioses with light coloration are truly compromised or simply extreme points on the spectrum 299 of natural color variation. Because Okinawa Island has been spared from major bleaching in 3002009 and 2014, it was impossible to test with this particular data set whether P. tuberculosa 301 functions as an "early indicator" species for the bleaching of scleractinian corals in the area, but 302 continued monitoring should provide the observations necessary to establish such a link if it 303 exists. Such work is needed to confirm the utility of a citizen science approach to monitoring 304 zoantharian color. 
305 Acknowledgements: We would like to thank the 12 participating members of the 2013-2014

306 "Kaiyo Seibutsu Seisan" Practical Course VII at the University of the Ryukyus and Taku Ohara 307 for their hard work and enthusiasm. 


\section{References}

310 Andréfouët S, Berkelmans R, Odriozola L, Done T, Oliver J, Müller-Karger F. 2002. Choosing

311 the appropriate spatial resolution for monitoring coral bleaching events using remote

312 sensing. Coral Reefs 21:147-154.

313 Brown BE. 1997. Coral bleaching: causes and consequences. Coral Reefs 16:S129-S138.

314 Cook CB, Logan A, Ward J, Luckhurst B, Berg Jr. CJ. 1990. Elevated temperatures and

315 bleaching on a high latitude coral reef: the 1988 Bermuda event. Coral Reefs 9:45-49.

316 Cooper TF, Gilmour JP, Fabricius KE. 2009. Bioindicators of changes n water quality on coral

317 reefs: review and recommendations for monitoring programmes. Coral Reefs 28:589-606.

318 Cruz IC, Leal MC, Mendes CR, Kikuchi RK, Rosa R, Soares AM, Serodio J, Calado R, Rocha RJ. 2015. White but not bleached: photophysiological evidence from white Montastrea cavernosa reveals potential overestimation of coral bleaching. Marine Biology 162:889899.

Dias TLP, Gondim AI. 2015. Bleaching in scleractinians, hydrocorals, and octocorals during thermal stress in a northeastern Brazilian reef. Marine Biodiversity DOI: $10.1007 / \mathrm{s} 12526-015-0342-8$

Donner SD, Skirving WJ, Little CM, Oppenheimer M, Hoegh-Guldberg O. 2005. Global assessment of coral bleaching and required rates of adaptation under climate change. Global Change Biology 11:2251-2265.

Depczynski M, Gilmour JP, Ridgway T, Barnes H, Heyward AJ, Holmes TH, Moore JAY, Radford BT, Thomson DP, Tinkler P, Wilson SK. 2013. Bleaching, coral mortality and subsequent survivorship on a West Australian fringing reef. Coral Reefs 32:233-238.

Eakin C, Lough J, Heron S. 2009. Climate variability and change: monitoring data and evidence for increased coral bleaching stress. In: Van Oppen MJH, Lough J, editors. Coral bleaching: patterns, processes, causes and consequences. Berlin: Springer, p 41-67.

334 Fitt WK, Brown BE, Warner ME, Dunne RP. 2001. Coral bleaching: interpretation of thermal tolerance limits and thermal thresholds in tropical corals. Coral Reefs 20:51-65.

Foster-Smith J, Evans SM. 2003. The v alue of marine ecological data collected by volunteers. Biological Conservation 113:199-213.

Glynn PW, Mate JL, Baker AC, Calderon MO. 2001. Coral bleaching and mortality in Panama 
340

341

342

343

344

345

346

347

348

349

350

351

352

353

354

355

356

357

358

359

360

361

362

363

364

365

366

367

368

patterns and comparisons with the 1982-1983 event. Bulletin of Marine Science 69:79109

Goldberg J, Wilkinson C. 2004. Global threats to coral reefs: coral bleaching, global climate change, disease, predator plagues and invasive species. In Wilkinson C, ed. Status of Coral Reefs of the World, 2004. Australian Institute of Marine Science, Townsville, Australia, 67-92.

Harvell D, Kim K, Quirolo C, Weir J, Smith G. 2001. Coral bleaching and disease: contributors to 1998 mass mortality in Briareum asbestinum (Octocorallia, Gorgonacea). Hydrobiologia 450:97-104

Hibino Y, Todd P, Ashworth CD, Obuchi M, Reimer JD. 2013. Monitoring colony colour and zooxanthellae (Symbiodinium spp.) condition in the reef zoanthid Palythoa tuberculosa in Okinawa, Japan. Marine Biology Research 9:794-801.

Hoegh-Guldberg O. 1999. Climate change, coral bleaching and the future of the world's coral reefs. Marine and Freshwater Research 50:839-866.

Hunter J, Alabri A, Ingen C. 2013. Assessing the quality and trustworthiness of citizen science data. Concurrency and Computation: Practice and Experience 25:454-466.

Jeffrey SW, Humphrey G. 1975. New spectrophotometric equations for determining chlorophylls a, b, c1 and c2 in higher plants, algae and natural phytoplankton. Biochemie und Physiologie der Pflanzen 167:191-194.

Krippendorff K. 2004. Reliability in content analysis. Human Communication Research 30:411433.

Kemp DW, Cook CB, LaJeunesse TC, Brooks WR. 2006. A comparison of the thermal bleaching responses of the zoanthid Palythoa caribaeorum from three geographically different regions in south Florida. Journal of Experimental Marine Biology and Ecology 335:266-276.

Kuroki T, Van Woesik R. 1999. Changes in zooxanthellae characteristics in the coral Stylophora pistillata during the 1998 bleaching event. Journal of the Japanese Coral Reef Society 1999:97-101.

Loya Y, Sakai K, Yamazato Y, Nakano, Y, Sambali H, Van Woesik R. 2001. Coral bleaching: the winners and the losers. Ecology Letters 4:122-131. 
370 Marshall NJ, Kleine DA, Dean AJ. 2012. CoralWatch: education, monitoring, and sustainability

371

372

373

374

375

376

377

378

379

380

381

382

383

384

385

386

387

388

389

390

391

392

393

394

395

396

397

398

399

through citizen science. Frontiers in Ecology and the Environment 10:332-334.

Mise T, Hidaka M. 2003. Degradation of zooxanthellae in the coral Acropora nasuta during bleaching. Galaxea JCRS 5:33-39.

Montano S, Seveso D, Galli P, Obura DO. 2010. Assessing coral bleaching and recovery with a colour reference card in Watamu Marine Park, Kenya. Hydrobiologia 655:99-108.

Neitz J, Jacobs GH. 1986. Polymorphism of the long-wavelength cone in normal human colour vision. Nature 323:623-625.

Paley AS, Bay LK. 2012. Bleaching condition varies among Acropora millepora colour morphs. Proceedings of the 12th International Coral Reef Symposium 1:1-5.

Prada C, Weil E, Yoshioka PM. 2010. Octocoral bleaching during unusual thermal stress. Coral Reefs 29:41-45.

Reimer JD, Ono S, Furushima Y, Tsukahara J. 2007. Seasonal changes in the morphological condition of symbiotic dinoflagellates (Symbiodinium spp.) of Zoanthus sansibaricus (Anthozoa: Hexacorallia) over a latitudinal range in southern Japan. South Pacific Studies 27:1-24.

Reimer JD, Takishita K, Ono S, Maruyama T. 2007. Diversity and evolution in the zoanthid genus Palythoa (Cnidaria:Hexacorallia) based on nuclear ITS-rDNA. Coral Reefs 26:399-410.

Richier S, Merle PL, Furla P, Pigozzi D, Sola F, Allemand D. 2003. Characterization of superoxide dismutases in anoxia- and hyperoxia-tolerant symbiotic cnidarians. Biochimica Et Biophysica Acta-General Subjects 1621:84-91.

Siebeck U, Logan D, Marshall N. 2008. CoralWatch: A flexible coral bleaching monitoring tool for you and your group. Proceedings of the 11th International Coral Reef Symposium 1:549-553.

Siebeck U, Marshall N, Klüter A, Hoegh-Guldberg O. 2006. Monitoring coral bleaching using a colour reference card. Coral Reefs 25:453-460.

Tanzil J. 2012. Bleaching susceptibility and growth characteristics of Porites lutea from the Andaman Sea, South Thailand. Phuket Marine Biology Center Research Bulletin 71:4956. 
400 Van Hooidonk R, Maynard J, Planes S. 2013. Temporary refugia for coral reefs in a warming 401 world. Nature Climate Change 3:508-511.

402 Wang J, Meng P, Sampayo E, Tang S, Chen C. 2011. Photosystem II breakdown induced by 403 reactive oxygen species in freshly-isolated Symbiodinium from Montipora (Scleractinia; 404 Acroporidae). Marine Ecology Progress Series 422:51-62.

405 West DA. 1979. Symbiotic zoanthids (Anthozoa: Cnidaria) of Puerto Rico. Bulletin of Marine 406 Science 29:253-271.

407 Williams EH, Bunkley-Williams L. 1990. The world-wide coral reef bleaching cycle and related $408 \quad$ sources of coral mortality. Atoll Research Bulletin 335:67.

409 Wilkinson C. 1998. The 1997-1998 mass bleaching event around the world. In Wilkinson C, ed. 410 Status of Coral Reefs of the World. Australian Institute of Marine Science, Townsville, 411 Australia, 15-38.

412 Winters G, Holzman R, Blekhman A, Beer S, Loya Y. 2009. Photographic assessment of coral 413 chlorophyll contents: Implications for ecophysiological studies and coral monitoring. 414 Journal of Experimental Marine Biology and Ecology 380:25-35. 
1

Color variation among unique colonies of Palythoa tuberculosa from reefs in Okinawa Island, Japan.

Colonies were photographed in January 2014 and standardized to the CoralWatch Coral Health Chart present in each image.

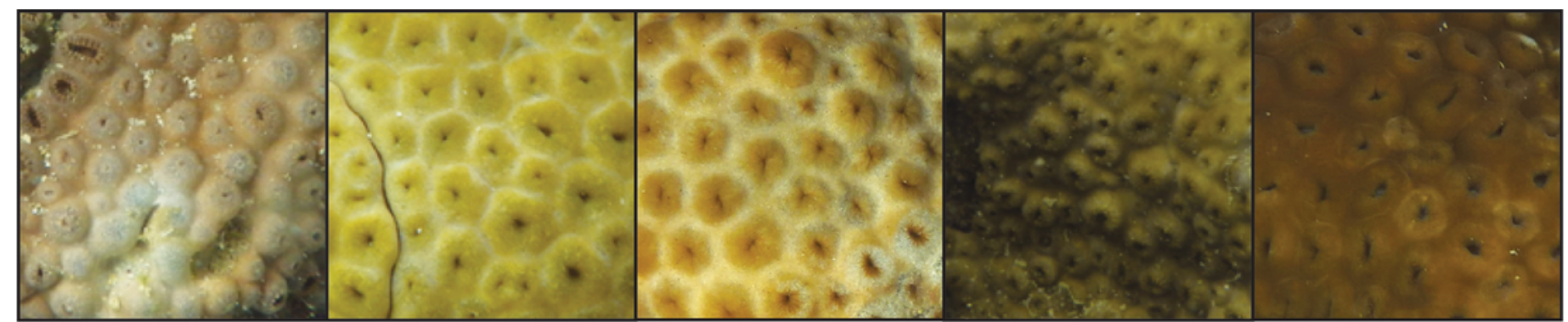

3.5

4.0

4.5

5.0

5.5 
2

Physiological characteristics of Palythoa tuberculosa colonies in January 2014.

(A.) Colony color score mean (dot), coefficient of variation (solid error bars), and range (dotted lines). $\mathrm{O}=$ Odo Beach, $\mathrm{M}=$ Mizugama. (B.) 'Normal zooxanthellae' percent, (C.) symbiont cell density, and (D.). chlorophyll a content per colony segregated by color score. Dashed black lines indicate linear regression fits. Gray shading indicates $95 \%$ confidence intervals. Rho values are Spearman correlation coefficients. Significance was assessed at $\alpha=$ 0.05 .

A.

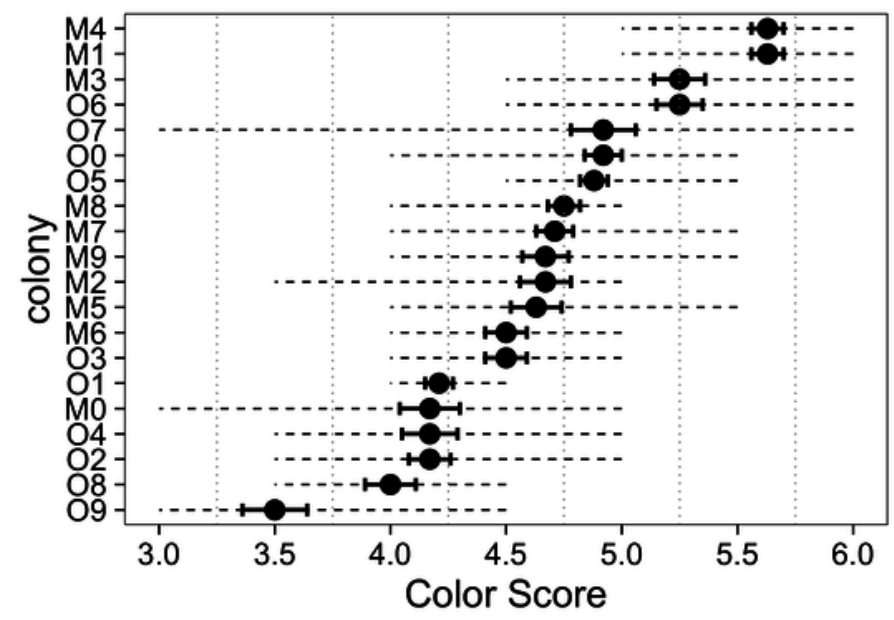

C.

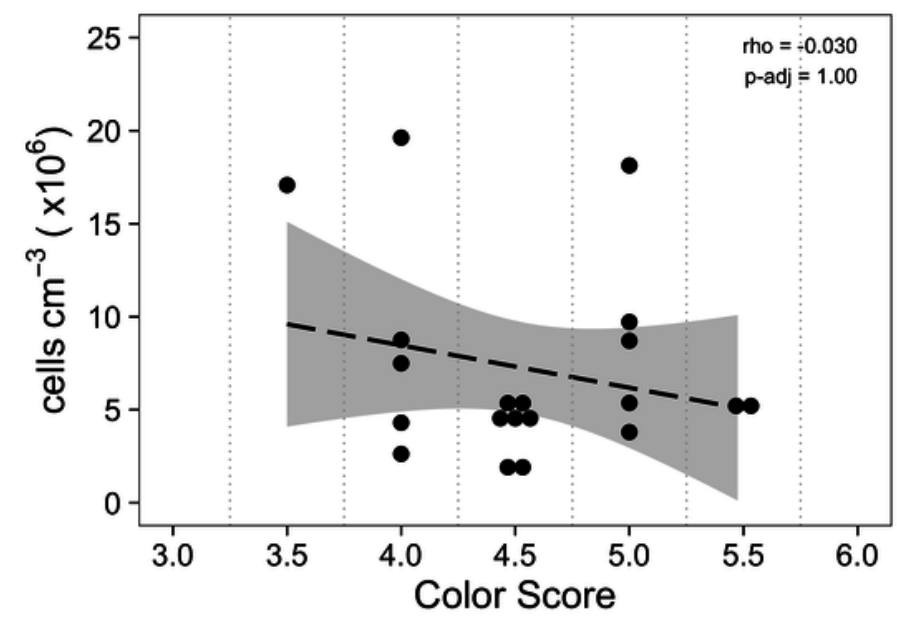

B.

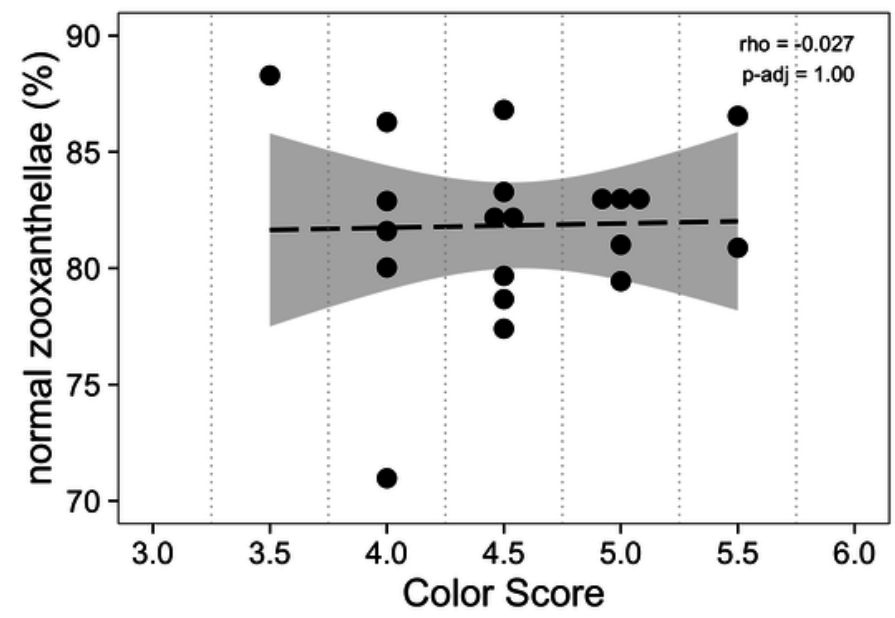

D.

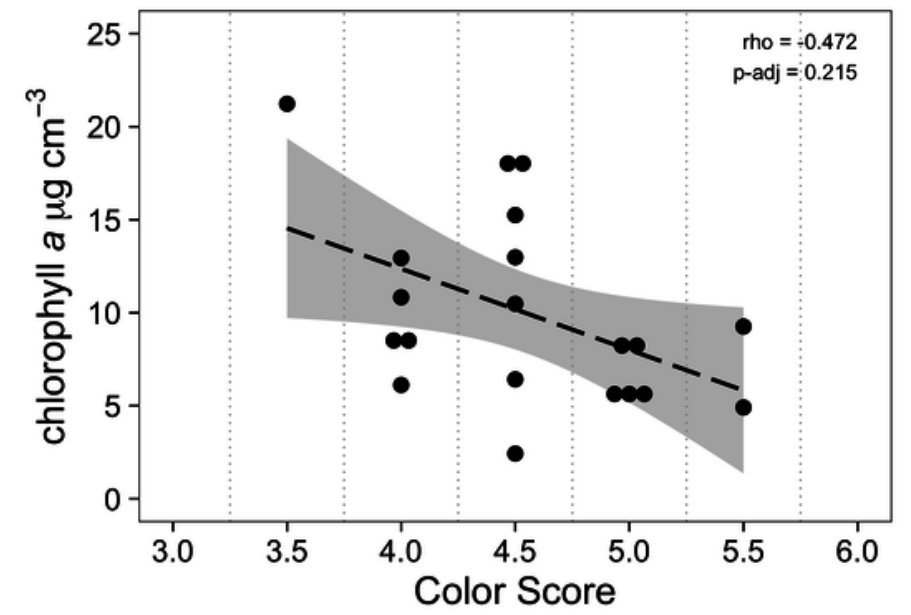


3

Previously published data from monthly monitoring of 12 Palythoa tuberculosa colonies from similar sites in Okinawa Island, Japan.

(A.) Color score distribution by month. (B.) Correlations (Spearman's rho) between colony color score and normal zooxanthellae percent by month. The dotted line indicates the region above which rho values are statistically significant for $\alpha=0.05$. Modified from Hibino et al. (2013) with permission.

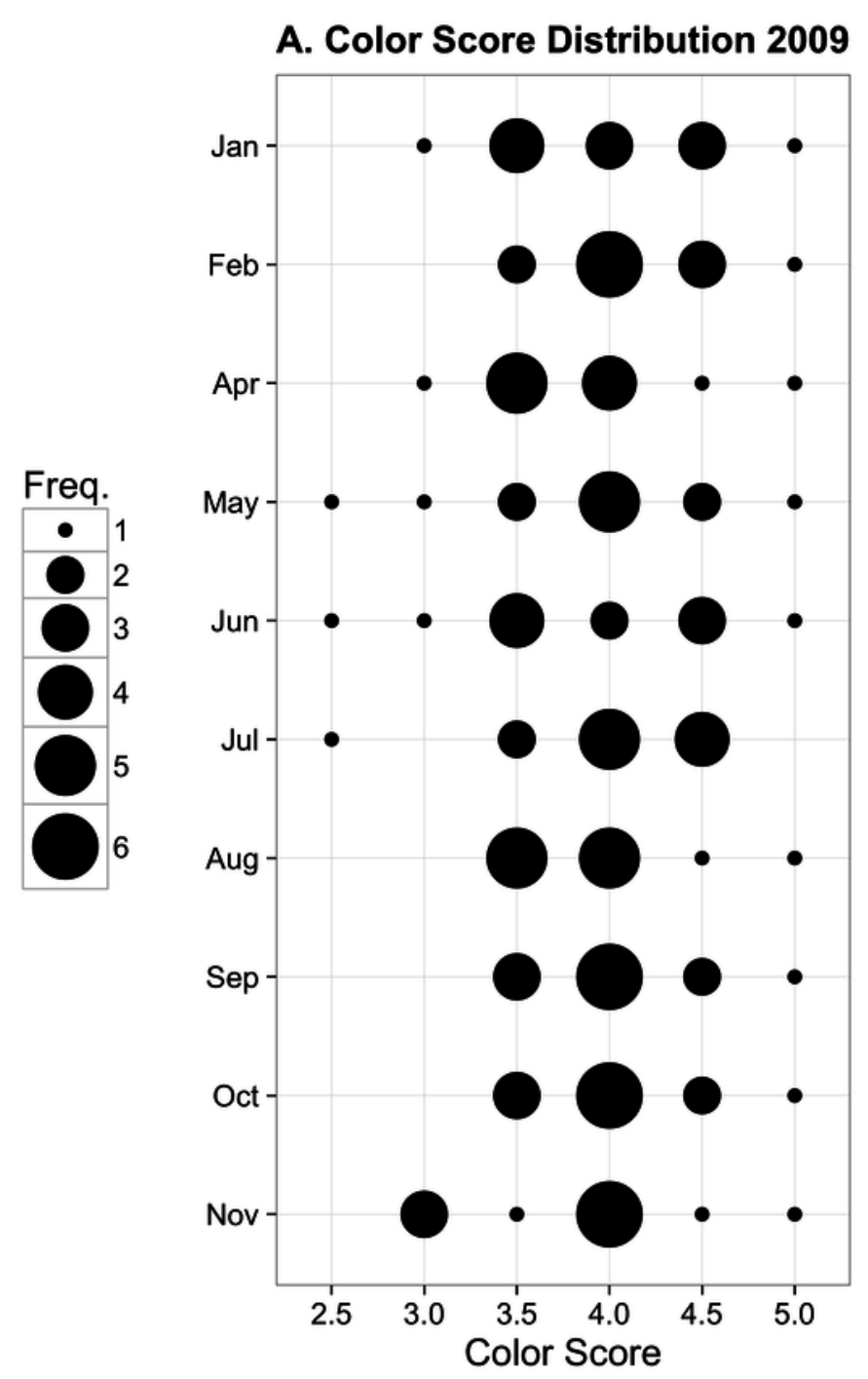

\section{B. Monthly NZ\% Correlations 2009}

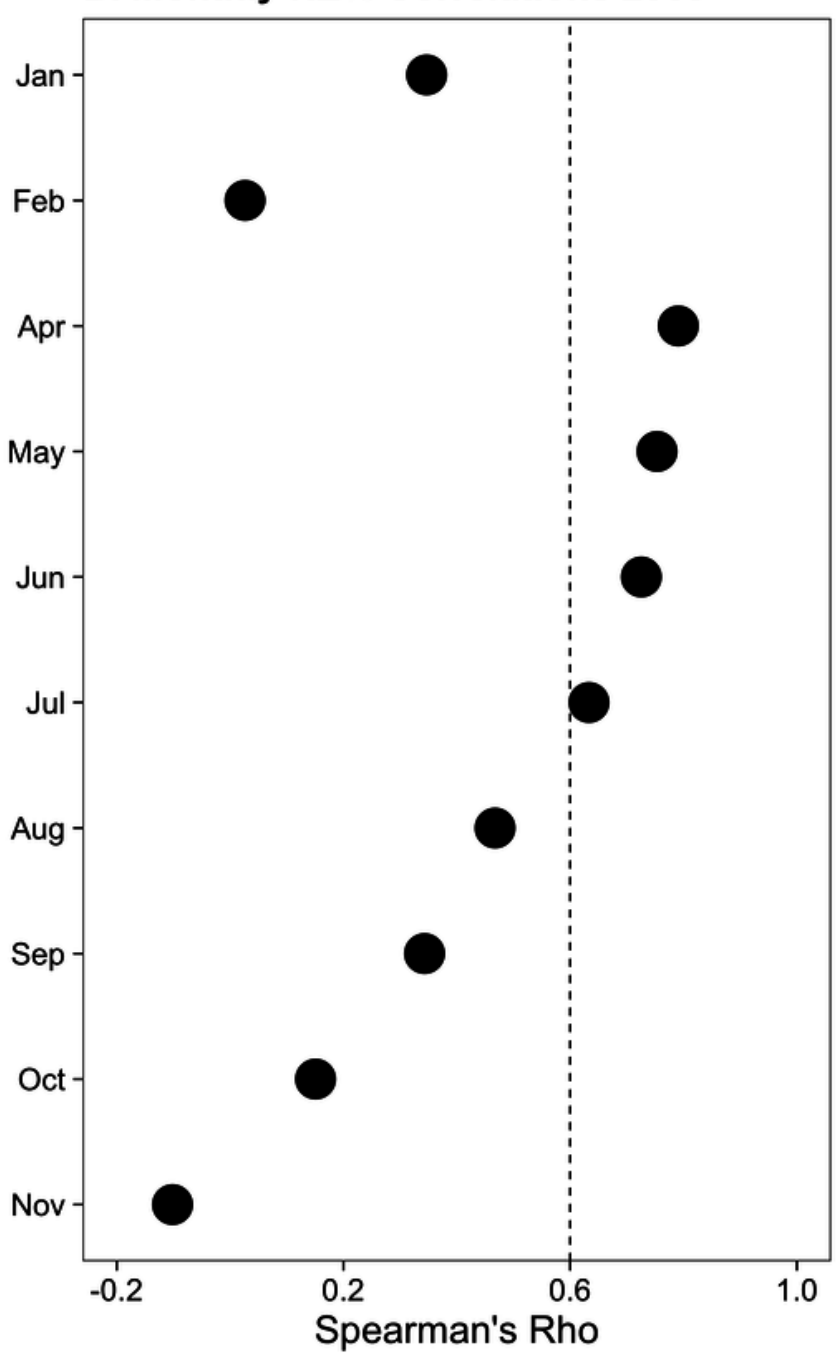




\section{4}

Normal zooxanthellae percent values segregated by color score for colonies of Palythoa tuberculosa.

(A.) May 2009, (B.) June 2009, (C.) January 2009, and (D.). January 2014. (A.) and (B.) represent summer months with large and significant correlation coefficients (Spearman's rho). (C.) and (D.) represent winter months with little correlation. Note that (A.), (B.), and (C.) represent the same set of repeatedly sampled colonies, whereas (D.) represents a unique set of colonies. Dashed black lines indicate linear regression fits. Gray shading indicates $95 \%$ confidence intervals. Rho values are Spearman correlation coefficients. Significance was assessed at $\alpha=0.05$. (A.), (B.), and (C.) modified from Hibino et al. (2013) with permission. 
A. May 2009

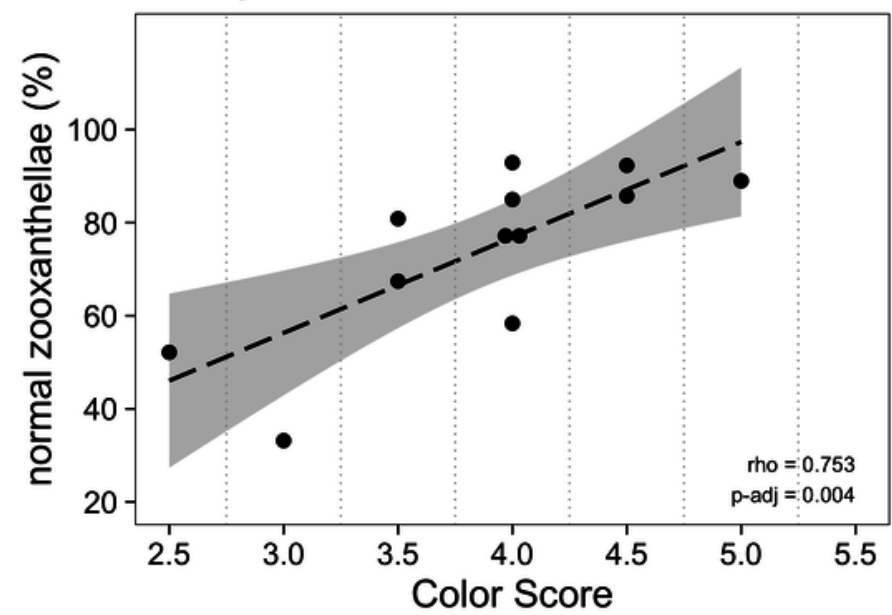

C. January 2009

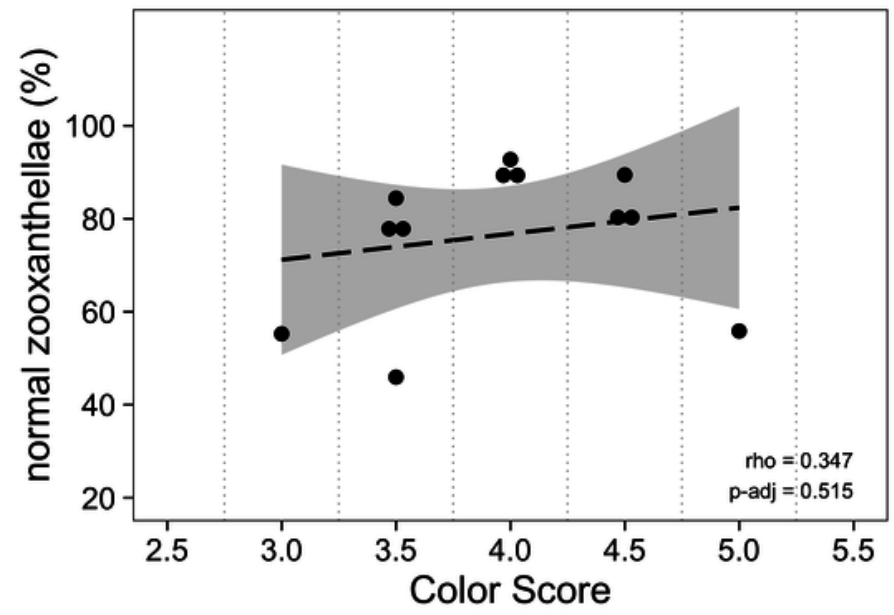

B. June 2009

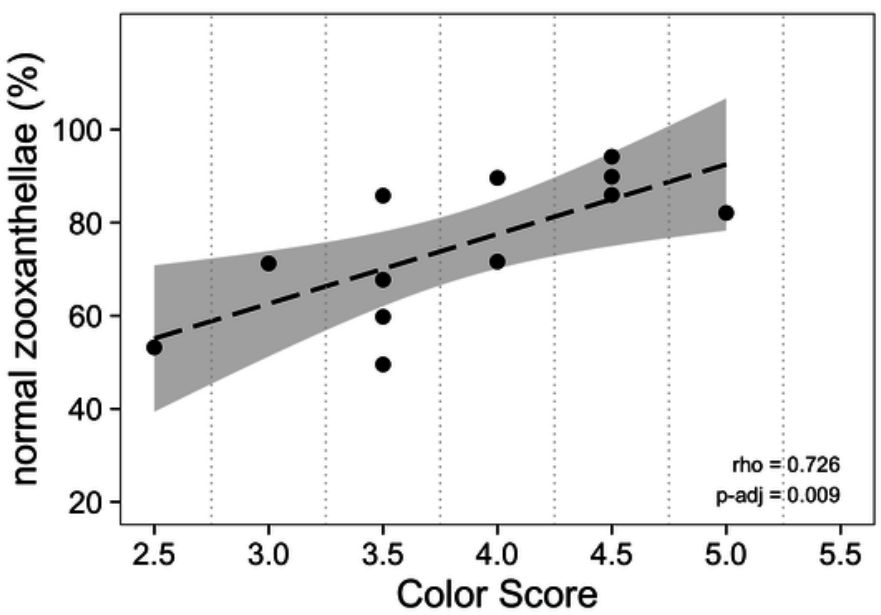

D. January 2014

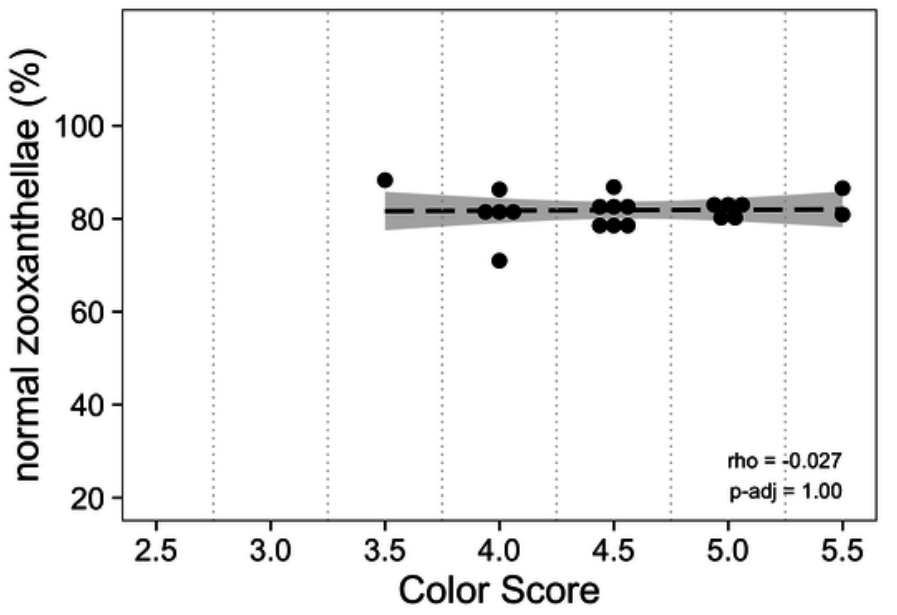

